\title{
ADSORPTION KINETICS OF DIRECT BLACK 38 ON NITROGEN-DOPED $\mathrm{TiO}_{2}$
}

\section{PAZ DIEGO S. DOTTO GUILHERME L.* MAZUTTI MARCIO A. FOLETTO EDSON L.}

Received: $15 / 04 / 2014$

Accepted: 28/05/2014

Available online: $23 / 06 / 2014$

\author{
Chemical Engineering Department \\ Federal University of Santa Maria \\ 97105-900, Santa Maria, Brazil
}

\section{ABSTRACT}

In this work, three samples of nitrogen-doped $\mathrm{TiO}_{2}$ prepared at different calcination temperatures (400, 450 and $500{ }^{\circ} \mathrm{C}$ ) were applied for the adsorption of Direct Black 38. Kinetic studies about the adsorption of Direct Black 38 on nitrogen-doped $\mathrm{TiO}_{2}$ were performed under different initial dye concentrations (75-175 $\left.\mathrm{mg} \mathrm{l}^{-1}\right)$. Pseudo-first and pseudo-second order models were fitted with the experimental data. The results revealed that nitrogen-doped $\mathrm{TiO}_{2}$ synthesized at $400{ }^{\circ} \mathrm{C}$ presented the more adequate characteristics for adsorption purposes, such as specific surface area of $151 \mathrm{~m}^{2} \mathrm{~g}^{-1}$. The adsorption kinetics agreed with the pseudo-second order model, at initial dye concentrations from 75 to $175 \mathrm{mg} \mathrm{I}^{-1}$. The maximum adsorption capacity predicted by the pseudo-second order model was $138.3 \mathrm{mg} \mathrm{g}^{-1}$, and was obtained using nitrogen-doped $\mathrm{TiO}_{2}$ synthesized at $400{ }^{\circ} \mathrm{C}$. In summary, these results revealed that nitrogen-doped $\mathrm{TiO}_{2}$ is a good material for the removal Direct Black 38 from aqueous solutions by adsorption.

Keywords: adsorption capacity, colored effluents, dye, pseudo-second order model.

\section{Introduction}

Traditional textile dyeing processes generate a large amount of colored effluents, because about $100 \mathrm{~L}$ of water are required to process $1 \mathrm{~kg}$ of dyed fabrics. These effluents are difficult to treat once the industrial textile dyes have been designed and synthesized to be highly resistant to washing, chemical agents, including solvents, and environmental factors (Uçar and Pazarlioglu, 2008). Due to the synthetic origin, recycling nature, as well as, complex aromatic structure, Direct Black 38 is one of the problematic and resistant organic pollutants into the colored effluents (Kamboh et al., 2014). Since that the inadequate release of dye containing effluents causes a series of environmental impacts; these effluents should be carefully treated before discharge (Saltabaş et al., 2012). However, the conventional treatment methods are very expensive and the low cost technologies don't allow a wishful colour removal and have certain disadvantages. Adsorption process has been found to be more effective method for the treatment of dye containing effluents. The most efficient and commonly used adsorbent is commercially activated carbon which is expensive and has regeneration problems (Verma and Mishra, 2010). In this way, the search for alternative adsorbents has gained attention (Verma and Mishra, 2010; El-Maghraby and El-Deeb, 2011; Saltabaş et al., 2012; Ramesh et al., 2014).

$\mathrm{TiO}_{2}$ is regarded as the most efficient and environmentally benign photocatalyst. It has been most widely used for photodegradation of various pollutants and is expected to play an important role in 
solving many serious environmental and pollution challenges (Collazzo et al., 2012a; Li et al., 2014). In heterogeneous photocatalysis using $\mathrm{TiO}_{2}$, it is reported that, an adsorption step of organic molecules occurs before the photocatalytic reaction (Bubacz et al., 2012; Collazzo et al., 2012a; Li et al., 2014). Thus, the knowledge of the adsorption phenomenon is very important for photocatalytic reactions. In a recent study, $\mathrm{TiO}_{2}$ powder was prepared by a hydrothermal process and simultaneously tested for the adsorption and photodegradation of Direct Black 38 (Collazzo et al., 2012b). Surface area value of 113 $\mathrm{m}^{2} \mathrm{~g}^{-1}$, and maximum adsorption capacity of $122 \mathrm{mg} \mathrm{g}^{-1}$ were found by the authors (Collazzo et al., 2012b).

Based on the above mentioned, and in order to improve the adsorption characteristics of $\mathrm{TiO}_{2}$, this work aimed to investigate the adsorption kinetics of Direct Black 38, a common dye used in tannery industry, on nitrogen-doped $\mathrm{TiO}_{2}$. Firstly, nitrogen-doped $\mathrm{TiO}_{2}$ samples were prepared at 400,450 and $500{ }^{\circ} \mathrm{C}$, and namely $\mathrm{TiO}_{2} \mathrm{~N} 400, \mathrm{TiO}_{2} \mathrm{~N} 450$ and $\mathrm{TiO}_{2} \mathrm{~N} 500$, respectively. These materials were then characterized according to the specific surface area, pore diameter and pore volume. After, kinetic studies were performed at different initial dye concentrations (75-175 $\left.\mathrm{mg} \mathrm{I}^{-1}\right)$. Pseudo-first and pseudo-second order models were used to interpret the experimental data.

\section{Material and Methods}

\subsection{Preparation and characterization of nitrogen-doped $\mathrm{TiO}_{2}$}

Nitrogen-doped $\mathrm{TiO}_{2}$ was synthesized according to Sun et al., (2008) and Paz et al., (2014). The samples were calcined at 400,450 and $500{ }^{\circ} \mathrm{C}$ and namely $\mathrm{TiO}_{2} \mathrm{~N} 400, \mathrm{TiO}_{2} \mathrm{~N} 450$ and $\mathrm{TiO}_{2} \mathrm{~N} 500$, respectively. This temperature range was applied according to Sun et al., (2008) and Sun et al., (2009). The detailed procedures and reagents can be found in Paz et al., (2014). The synthesized samples, in a yellow powder form, were characterized by X-ray diffraction (shown in Paz et al., 2014), which presented only a crystalline anatase structure. Herein, these samples were characterized by specific surface area, pore diameter and pore volume. These characterizations were made by a volumetric adsorption analyzer (Quantachrome Instruments, New Win 2, USA) using the Bennett, Emmet and Teller (BET) method (Leyva-Ramos et al., 2012).

\subsection{Adsorption experiments}

Direct Black 38 (purity of 98\%) (tri azo dye, C.I. number 30235, molecular formula $\mathrm{C}_{34} \mathrm{H}_{28} \mathrm{~N}_{9} \mathrm{O}_{8} \mathrm{~S}_{2} \mathrm{Na}_{2}$ and molecular weight $\left.781.7 \mathrm{~g} \mathrm{~mol}^{-1}\right)$ was employed as model molecule in this study. Stock solutions $\left(1.0 \mathrm{~g} \mathrm{I}^{-1}\right)$ (Moreira et al., 2005) were prepared and all subsequent tests were made by dilution of these solutions.

For the three adsorbent samples $\left(\mathrm{TiO}_{2} \mathrm{~N} 400, \mathrm{TiO}_{2} \mathrm{~N} 450\right.$ and $\left.\mathrm{TiO}_{2} \mathrm{~N} 500\right)$, the adsorption experiments were carried out using batch systems at different initial dye concentrations $\left(75,100,125,150\right.$ and $\left.175 \mathrm{mg} \mathrm{I}^{-1}\right)$, optimum pH of 2.5 (Moreira et al., 2005), temperature of $25^{\circ} \mathrm{C}$ and adsorbent dosage of $1.0 \mathrm{~g} \mathrm{I}^{-1}$. Firstly, $0.100 \mathrm{~g}$ of adsorbent was added into $100 \mathrm{ml}$ of dye solutions with the desired initial concentration. The system was agitated at $100 \mathrm{rpm}$ in a thermostated shaker (Fanem, $315 \mathrm{SE}$, Brazil) until the equilibrium. Aliquots were withdrawn in preset time intervals, centrifuged (Centribio, 80-2B, Brazil) and filtered in a PVDF membrane $(0.22 \mu \mathrm{m})$. The remaining dye (Direct Black 38$)$ concentration was determined by spectrophotometry (Spectro vision, T6-UV, Brazil) at $\lambda_{\max }=590 \mathrm{~nm}$. UV-vis absorption spectrum of Direct Black 38 aqueous solution at pH 2.5 was shown in a previous study (Moreira et al., 2005), and present one band in the visible region with its maximum located at $590 \mathrm{~nm}$. All experiments were carried out in replicate $(n=2)$ and blanks were performed. Only the mean values were presented in the results (the maximum experimental error was 5.78\%). The amount of dye adsorbed per gram of adsorbent, $q_{t}\left(\mathrm{mg} \mathrm{g}^{-1}\right)$ at any time, $t(\mathrm{~min})$ was determined by the Equation 1 :

$\mathrm{q}_{\mathrm{t}}=\frac{\mathrm{C}_{0}-\mathrm{C}_{\mathrm{t}}}{\mathrm{m}} \mathrm{v}$ 
where, $C_{0}$ is the initial dye concentration in liquid phase $\left(\mathrm{mg} \mathrm{I}^{-1}\right), C_{t}$ is the dye concentration in liquid phase at time $\mathrm{t}\left(\mathrm{mg} \mathrm{l}^{-1}\right), \mathrm{m}$ is the adsorbent amount $(\mathrm{g})$ and $\mathrm{V}$ is the volume of solution (I).

\subsection{Kinetic models}

In solid-liquid adsorption systems, the kinetic study is fundamental. From the kinetic analysis, the solute uptake rate, which determines the residence time required for completion of adsorption process, may be established. This study explains how fast the adsorption occurs and also provides information on the factors affecting the process (Dotto and Pinto, 2012; Dotto et al., 2012; 2013). In this work, the pseudofirst and pseudo-second order models were fitted with the experimental data in order to elucidate the adsorption kinetic behavior of Direct Black 38 dye on nitrogen-doped $\mathrm{TiO}_{2}$. The kinetic models of pseudo-first order (Lagergren, 1898) and pseudo-second order (Ho and McKay, 1998) are based in the adsorption capacity. The pseudo-first order model (Equation (2)) is generally applicable over the initial 20-30 min of the sorption process, while the pseudo-second order model (Equation (3)) is suitable for the whole range of contact time (Liu and Liu, 2008).

$$
\begin{aligned}
& q_{t}=q_{1}\left(1-\exp \left(-k_{1} t\right)\right) \\
& q_{t}=\frac{t}{\left(1 / k_{2} q_{2}{ }^{2}\right)+\left(t / q_{2}\right)}
\end{aligned}
$$

being, $k_{1}$ and $k_{2}$ the rate constants of pseudo-first order and pseudo-second order models, respectively, in $\left(\mathrm{min}^{-1}\right)$ and $\left(\mathrm{g} \mathrm{mg}^{-1} \mathrm{~min}^{-1}\right), \mathrm{q}_{1}$ and $\mathrm{q}_{2}$ are the theoretical values for the adsorption capacity (mg $\left.{ }^{-1}\right)$. Furthermore, for the pseudo-second order model, the initial sorption rate, $h_{0}\left(\mathrm{mg} \mathrm{g}^{-1} \mathrm{~min}^{-1}\right)$ can be defined by the Equation 4 (Ho and McKay, 1998):

$$
\mathrm{h}_{0}=\mathrm{k}_{2}\left(\mathrm{q}_{2}\right)^{2}
$$

The kinetic parameters were determined by the fit of the models (Equations 2 and 3) with the experimental data through nonlinear regression using the Quasi-Newton estimation method. The calculations were carried out by the Statistic 7.0 software (Statsoft, USA). The fit quality and the accuracy of the kinetic parameters were measured through determination coefficient $\left(R^{2}\right)$ and average relative error (ARE) (El-Khaiary and Malash, 2011).

\section{Results and discussion}

\subsection{Characteristics of nitrogen-doped $\mathrm{TiO}_{2}$}

The results of specific surface area $\left(\mathrm{S}_{\mathrm{BET}}\right)$, pore diameter and pore volume for $\mathrm{TiO}_{2} \mathrm{~N} 400, \mathrm{TiO}_{2} \mathrm{~N} 450$ and $\mathrm{TiO}_{2} \mathrm{~N} 500$ are shown in Table 1. Figure 1 shows the $\mathrm{N}_{2}$ adsorption/desorption isotherms for (a) $\mathrm{TiO}_{2} \mathrm{~N} 400$, (b) $\mathrm{TiO}_{2} \mathrm{~N} 450$ and (c) $\mathrm{TiO}_{2} \mathrm{~N} 500$.

It was found in Table 1, that the specific surface area of $\mathrm{TiO}_{2} \mathrm{~N} 400$ was very higher than specific surface areas of $\mathrm{TiO}_{2} \mathrm{~N} 450$ and $\mathrm{TiO}_{2} \mathrm{~N} 500$. The pore diameter of $\mathrm{TiO}_{2} \mathrm{~N} 400$ was the same that $\mathrm{TiO}_{2} \mathrm{~N} 450$, and higher than the $\mathrm{TiO}_{2} \mathrm{~N} 500$. The pore volume of $\mathrm{TiO}_{2} \mathrm{~N} 400$ was in the same magnitude that $\mathrm{TiO}_{2} \mathrm{~N} 450$, and higher than the $\mathrm{TiO}_{2} \mathrm{~N} 500$. These results indicated that $\mathrm{TiO}_{2} \mathrm{~N} 400$ presented the more adequate characteristics for adsorption purposes. In general lines, the $\mathrm{N}_{2}$ adsorption/desorption isotherms (Figure 1) were similar to the type IV isotherm, according to the IUPAC classification. This shows that the nitrogen-doped $\mathrm{TiO}_{2}$ samples obtained in this work are predominantly mesoporous materials.

Table 1 Specific surface area $\left(\mathrm{S}_{\mathrm{BET}}\right)$, pore diameter and pore volume results

\begin{tabular}{cccc}
\hline Sample & $\mathrm{S}_{\mathrm{BET}}\left(\mathrm{m}^{2} \mathrm{~g}^{-1}\right)^{*}$ & Pore diameter $(\mathrm{nm})^{*}$ & Pore volume $\left(\mathrm{cm}^{3} \mathrm{~g}^{-1}\right)^{*}$ \\
\hline $\mathrm{TiO}_{2} \mathrm{~N} 400$ & $151 \pm 3$ & $3.48 \pm 0.25$ & $0.0119 \pm 0.0009$ \\
$\mathrm{TiO}_{2} \mathrm{~N} 450$ & $49 \pm 2$ & $3.86 \pm 0.28$ & $0.0360 \pm 0.0015$ \\
$\mathrm{TiO}_{2} \mathrm{~N} 500$ & $13 \pm 2$ & $2.62 \pm 0.21$ & $0.0003 \pm 0.0001$ \\
\hline
\end{tabular}

*mean \pm standard error $(n=3)$. 

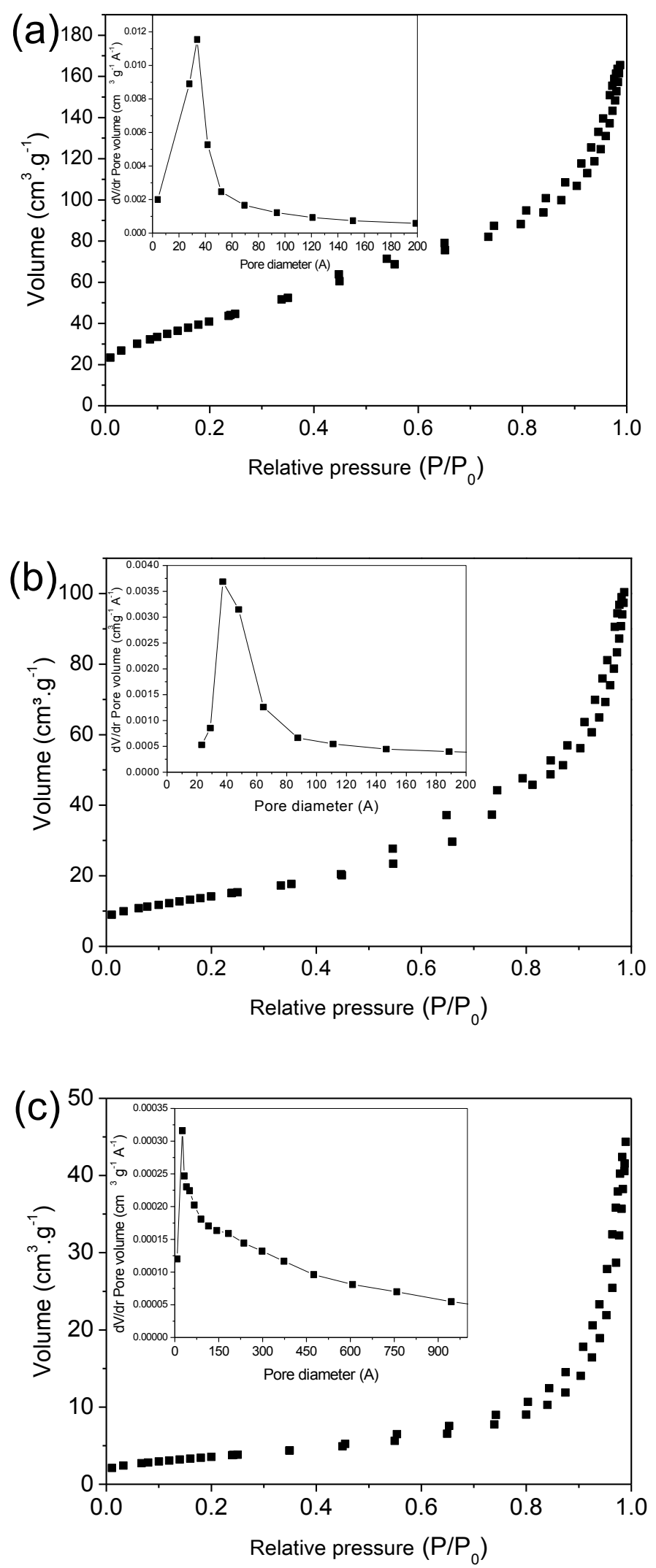

Figure 1. $\mathrm{N}_{2}$ adsorption/desorption isotherms for (a) $\mathrm{TiO}_{2} \mathrm{~N} 400$, (b) $\mathrm{TiO}_{2} \mathrm{~N} 450$ and (c) $\mathrm{TiO}_{2} \mathrm{~N} 500$ 


\subsection{Kinetic analysis}

In this work, kinetic curves for the adsorption of Direct Black 38 on $\mathrm{TiO}_{2} \mathrm{~N} 400, \mathrm{TiO}_{2} \mathrm{~N} 450$ and $\mathrm{TiO}_{2} \mathrm{~N} \mathrm{OOO}$ were obtained at different initial dye concentrations $\left(75,100,125,150\right.$ and $175 \mathrm{mg} \mathrm{l}^{-1}$ ). These kinetic curves are shown in Figure 2.
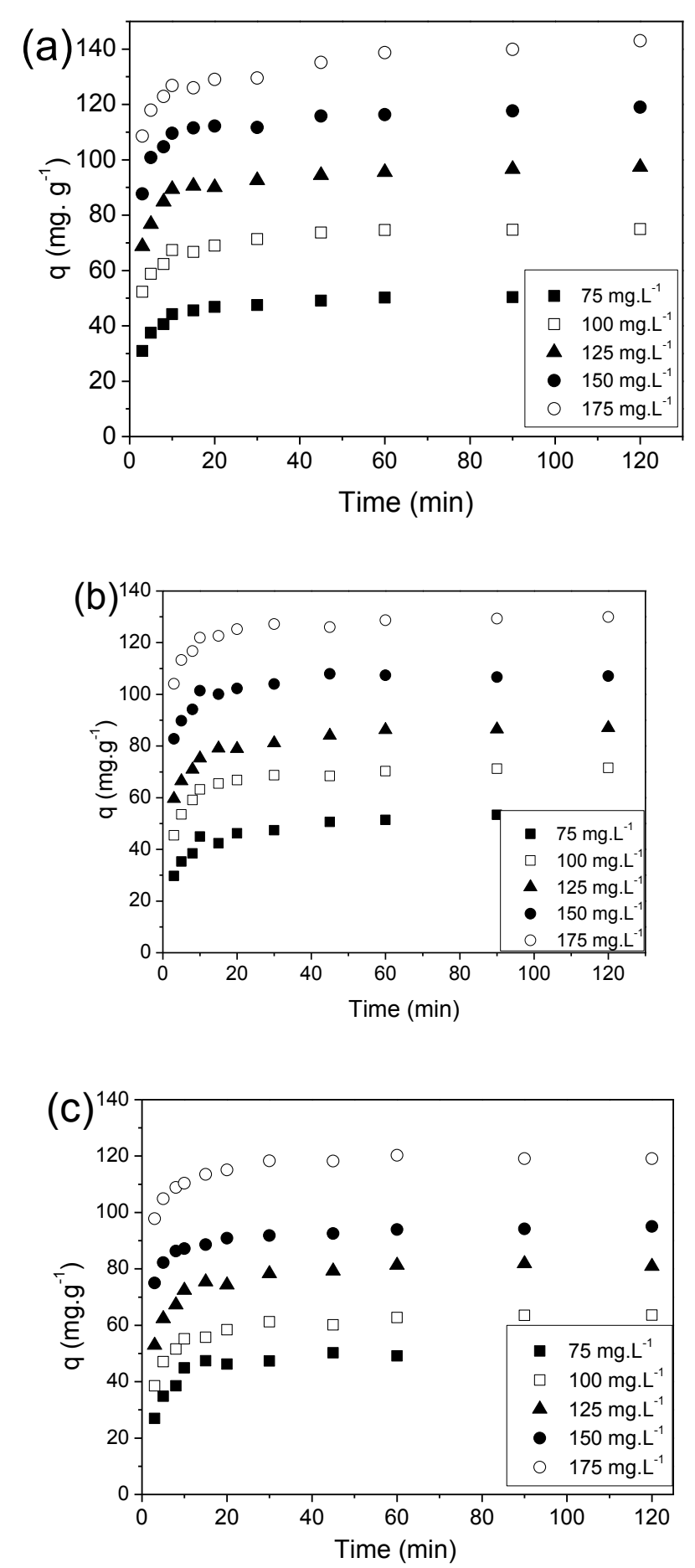

Figure 2. Kinetic curves for the adsorption of Direct Black 38 on (a) $\mathrm{TiO}_{2} \mathrm{~N} 400$, (b) $\mathrm{TiO}_{2} \mathrm{~N} 450$ and (c) $\mathrm{TiO}_{2} \mathrm{~N} 500$ at different initial dye concentrations.

( $\mathrm{pH}$ of 2.5 , temperature of $25^{\circ} \mathrm{C}$ and adsorbent dosage $1 \mathrm{~g} \mathrm{I}^{-1}$ ) 
It can be seen in Figure 2, for all kinetic curves, that the adsorption of Direct Black 38 on $\mathrm{TiO}_{2} \mathrm{~N}_{400}$, $\mathrm{TiO}_{2} \mathrm{~N} 450$ and $\mathrm{TiO}_{2} \mathrm{~N} 500$ was a fast process. It was found a fast increase in the adsorption capacity until $20 \mathrm{~min}$. After this time, the adsorption rate decreased considerably, being the equilibrium attained at about 60 min (Figure 2). This information is particularly important for the treatment of colored effluents, because, the process (adsorption + photocatalysis) can be performed without illumination until 60 min. Similar trend was found by Collazzo et al., (2012b) in the adsorption of Direct Black 38 dye on $\mathrm{TiO}_{2}$ prepared at low temperature.

Regarding the initial dye concentration effect, it was verified that and increase from 75 to $175 \mathrm{mg} \mathrm{I}^{-1}$ caused an increase of two-three fold in the adsorption capacity (Figure 2). This occurred due to the higher driving force for adsorption at higher concentrations, which affects the external and internal mass transfer mechanisms (Dotto and Pinto, 2012; Leyva-Ramos et al., 2012). Similar trend was found by Fil et al. (2013) in the adsorption of Basic Red 18 on natural Turkish clay.

The pseudo-first and pseudo-second order models were fitted with the experimental data in order to elucidate the adsorption kinetic behavior of Direct Black 38 on nitrogen-doped $\mathrm{TiO}_{2}$. The results are shown in Tables $2\left(\mathrm{TiO}_{2} \mathrm{~N} 400\right), 3\left(\mathrm{TiO}_{2} \mathrm{~N} 450\right)$ and $4\left(\mathrm{TiO}_{2} \mathrm{~N} 500\right)$, respectively.

Table 2 Kinetic parameters for the adsorption of Direct Black 38 on $\mathrm{TiO}_{2} \mathrm{~N} 400$.

\begin{tabular}{cccccc}
\hline & \multicolumn{5}{c}{ Initial dye concentration $\left(\mathrm{mg} \mathrm{I}^{-1}\right)$} \\
\cline { 2 - 6 } & 75 & 100 & 125 & 150 & 175 \\
\hline Pseudo-first order model & \multicolumn{5}{c}{} \\
\hline $\mathrm{q}_{1}\left(\mathrm{mg} \mathrm{g}^{-1}\right)$ & 48.5 & 71.4 & 93.1 & 113.8 & 132.7 \\
$\mathrm{k}_{1}\left(\mathrm{~min}^{-1}\right)$ & 0.290 & 0.373 & 0.389 & 0.455 & 0.509 \\
$\mathrm{R}^{2}$ & 0.9807 & 0.9747 & 0.9870 & 0.9898 & 0.9759 \\
$\mathrm{ARE}(\%)$ & 3.78 & 4.14 & 3.01 & 2.50 & 3.94 \\
\hline Pseudo-second order model & 51.5 & 75.2 & 97.6 & 118.5 & 138.3 \\
\hline $\mathrm{q}_{2}\left(\mathrm{mg} \mathrm{g}^{-1}\right)$ & 0.0099 & 0.0094 & 0.0081 & 0.0085 & 0.0080 \\
$\mathrm{k}_{2}\left(\mathrm{~g} \mathrm{mg}^{-1} \mathrm{~min}^{-1}\right)$ & 26.27 & 53.32 & 77.52 & 119.51 & 152.50 \\
$\mathrm{~h}_{0}\left(\mathrm{mg} \mathrm{g}^{-1} \mathrm{~min}^{-1}\right)$ & 0.9985 & 0.9968 & 0.9981 & 0.9982 & 0.9933 \\
$\mathrm{R}^{2}$ & 0.93 & 1.42 & 0.91 & 0.95 & 1.83 \\
\hline $\mathrm{ARE}(\%)$ & 51.3 & 75.0 & 97.4 & 119.0 & 138.9 \\
\hline $\mathrm{q}_{\mathrm{e}} \exp \left(\mathrm{mg} \mathrm{g}^{-1}\right)$ & & & &
\end{tabular}

Table 3 Kinetic parameters for the adsorption of Direct Black 38 on $\mathrm{TiO}_{2} \mathrm{~N} 450$.

\begin{tabular}{cccccc}
\hline & \multicolumn{5}{c}{ Initial dye concentration $\left(\mathrm{mg} \mathrm{I}^{-1}\right)$} \\
\cline { 2 - 6 } & 75 & 100 & 125 & 150 & 175 \\
\hline Pseudo-first order model & \multicolumn{5}{c}{} \\
\hline $\mathrm{q}_{1}\left(\mathrm{mg} \mathrm{g}^{-1}\right)$ & 49.2 & 68.5 & 82.2 & 103.9 & 125.5 \\
$\mathrm{k}_{1}\left(\mathrm{~min}^{-1}\right)$ & 0.244 & 0.312 & 0.353 & 0.464 & 0.538 \\
$\mathrm{R}^{2}$ & 0.9567 & 0.9861 & 0.9716 & 0.9844 & 0.9901 \\
$\mathrm{ARE}(\%)$ & 5.68 & 3.02 & 4.48 & 4.52 & 2.36 \\
\hline Pseudo-second order model & 52.9 & 72.5 & 86.9 & 108.2 & 129.8 \\
\hline $\mathrm{q}_{2}\left(\mathrm{mg} \mathrm{g}^{-1}\right)$ & 0.0074 & 0.0079 & 0.0076 & 0.0095 & 0.0102 \\
$\mathrm{k}_{2}\left(\mathrm{~g} \mathrm{mg}^{-1} \mathrm{~min}^{-1}\right)$ & 20.80 & 41.58 & 57.10 & 111.36 & 172.05 \\
$\mathrm{~h}_{0}\left(\mathrm{mg} \mathrm{g}^{-1} \mathrm{~min}^{-1}\right)$ & 0.9887 & 0.9989 & 0.9971 & 0.9977 & 0.9992 \\
$\mathrm{R}^{2}$ & 2.68 & 0.69 & 1.31 & 1.14 & 0.63 \\
\hline $\mathrm{ARE}(\%)$ & 51.8 & 71.5 & 87.0 & 107.1 & 129.9 \\
\hline $\mathrm{q}_{\mathrm{e}} \exp \left(\mathrm{mg} \mathrm{g}^{-1}\right)$ & & & &
\end{tabular}


Table 4 Kinetic parameters for the adsorption of Direct Black 38 on $\mathrm{TiO}_{2} \mathrm{~N} 500$.

\begin{tabular}{cccccc}
\hline & \multicolumn{5}{c}{ Initial dye concentration $\left(\mathrm{mg} \mathrm{I}^{-1}\right)$} \\
\cline { 2 - 6 } & 75 & 100 & 125 & 150 & 175 \\
\hline Pseudo-first order model & \multicolumn{5}{c}{} \\
\hline $\mathrm{q}_{1}\left(\mathrm{mg} \mathrm{g}^{-1}\right)$ & 48.8 & 60.5 & 78.1 & 91.3 & 116.0 \\
$\mathrm{k}_{1}\left(\mathrm{~min}^{-1}\right)$ & 0.241 & 0.294 & 0.324 & 0.526 & 0.559 \\
$\mathrm{R}^{2}$ & 0.9883 & 0.9805 & 0.9822 & 0.9899 & 0.9883 \\
$\mathrm{ARE}(\%)$ & 2.92 & 3.70 & 3.44 & 2.49 & 2.74 \\
\hline Pseudo-second order model & 52.1 & 64.3 & 82.6 & 94.6 & 120.0 \\
\hline $\mathrm{q}_{2}\left(\mathrm{mg} \mathrm{g}^{-1}\right)$ & 0.0078 & 0.0082 & 0.0072 & 0.0133 & 0.0115 \\
$\mathrm{k}_{2}\left(\mathrm{~g} \mathrm{mg}^{-1} \mathrm{~min}^{-1}\right)$ & 21.19 & 34.08 & 49.52 & 119.51 & 165.67 \\
$\mathrm{~h}_{0}\left(\mathrm{mg} \mathrm{g}^{-1} \mathrm{~min}^{-1}\right)$ & 0.9896 & 0.9977 & 0.9981 & 0.9995 & 0.9991 \\
$\mathrm{R}^{2}$ & 2.60 & 1.19 & 1.01 & 0.51 & 0.65 \\
\hline ARE (\%) & 50.6 & 63.6 & 80.9 & 95.0 & 119.1 \\
\hline $\mathrm{q}_{\mathrm{e}} \exp \left(\mathrm{mg} \mathrm{g}^{-1}\right)$ & & & & &
\end{tabular}

The high values of the determination coefficient $\left(R^{2}>0.9887\right)$ and the low values of average relative error (ARE $<2.70 \%$ ) presented in Tables 2, 3 and 4, demonstrated that the pseudo-second order model was the more adequate to represent the adsorption of Direct Black 38 on nitrogen-doped $\mathrm{TiO}_{2}$. This fact is corroborated, since the pseudo-second order model predicted very well the experimental equilibrium adsorption capacity $\left(q_{e}\right.$ exp) with maximum error of $3 \%$, while, the pseudo-first order model underestimated the $\mathrm{q}_{\mathrm{e}}$ exp values in all cases (Tables 2, 3 and 4).

From Tables $2\left(\mathrm{TiO}_{2} \mathrm{~N} 400\right), 3\left(\mathrm{TiO}_{2} \mathrm{~N} 450\right)$ and $4\left(\mathrm{TiO}_{2} \mathrm{~N} 500\right)$, it was observed that the equilibrium adsorption capacity predicted by the pseudo-second order model $\left(q_{2}\right)$ increased as a function of the initial dye concentration increase. For all adsorbents, the maximum values for $q_{2}$ were found at $175 \mathrm{mg} \mathrm{l}^{-1}$. This occurred because at high initial dye concentrations, more dye is transferred from the bulk solution to the adsorbent surface, and so, more dye molecules occupies the adsorption sites (since that, in the concentration range of this work, the monolayer saturation was not attained). Another fact in relation to the $q_{2}$ values at $175 \mathrm{mg} \mathrm{l}^{-1}$ is the following: $q_{2}$ of $\mathrm{TiO}_{2} \mathrm{~N} 400>\mathrm{q}_{2}$ of $\mathrm{TiO}_{2} \mathrm{~N} 450>\mathrm{q}_{2}$ of $\mathrm{TiO}_{2} \mathrm{~N}^{2} 00$. This behavior can be explained on the basis in the specific surface area values of the adsorbents (Table 1), which presented the same dependence. According to Ruthven (1984), the adsorption capacity is directly proportional to the specific surface area of the adsorbent. Based on these results it can be concluded that nitrogen-doped $\mathrm{TiO}_{2}$ synthesized at $400{ }^{\circ} \mathrm{C}$ presented the more adequate characteristics for adsorption purposes, such as specific surface area of $151 \mathrm{~m}^{2} \mathrm{~g}^{-1}$ and adsorption capacity of $138.3 \mathrm{mg} \mathrm{g}^{-1}$.

The initial sorption rate $\left(h_{0}\right)$ (Tables 2, 3 and 4 ) values increased with the initial dye concentration. This shows that, at the initial stages of the adsorption process, more dye was faster adsorbed at higher initial dye concentrations. Similar results were found by Cardoso et al., (2012) in the adsorption of Reactive red 120 on activated carbon and Spirulina platensis. Finally, any clear tendency was noted regarding to the $k_{2}$ parameter (Tables 2, 3 and 4).

\section{Conclusions}

In this work, the adsorption kinetics of Direct Black 38 dye on nitrogen-doped $\mathrm{TiO}_{2}$ was studied. Firstly, nitrogen-doped $\mathrm{TiO}_{2}$ samples were prepared at 400,450 and $500{ }^{\circ} \mathrm{C}$, aiming to improve its adsorption characteristics. After, adsorption kinetic studies were carried out to verify the behavior of nitrogendoped $\mathrm{TiO}_{2}$. From the results, it was found that the nitrogen-doped $\mathrm{TiO}_{2}$ samples obtained in this work were predominantly mesoporous materials, and the specific surface areas were 151,49 and $13 \mathrm{~m}^{2} \mathrm{~g}^{-1}$, respectively, for $\mathrm{TiO}_{2} \mathrm{~N} 400, \mathrm{TiO}_{2} \mathrm{~N} 450$ and $\mathrm{TiO}_{2} \mathrm{~N} 500$. This indicated that nitrogen-doped $\mathrm{TiO}_{2}$ synthesized at $400{ }^{\circ} \mathrm{C}$ presented the more adequate characteristics for adsorption purposes. The kinetic curves presented a fast increase in the adsorption capacity until $20 \mathrm{~min}$, being the equilibrium attained at 
about $60 \mathrm{~min}$. The values of $R^{2}$ and $A R E$ demonstrated that the pseudo-second order model was the more adequate to represent the adsorption of Direct Black 38 on nitrogen-doped $\mathrm{TiO}_{2}$. The maximum adsorption capacity was $138.3 \mathrm{mg} \mathrm{g}^{-1}$, and was obtained using nitrogen-doped $\mathrm{TiO}_{2}$ synthesized at $400{ }^{\circ} \mathrm{C}$. In brief, these results revealed that nitrogen-doped $\mathrm{TiO}_{2}$ is a good material for the treatment of colored effluents, since that, before its photocatalytic action, a considerable amount of dye are adsorbed.

\section{Acknowledgments}

The authors would like to thank CAPES (Coordination for the Improvement of Higher Education Personnel) and CNPq (National Council for Scientific and Technological Development) for the financial support.

\section{References}

Bubacz K., Tryba B. and Morawski A.W. (2012), The role of adsorption in decomposition of dyes on $\mathrm{TiO}_{2}$ and n-modified $\mathrm{TiO}_{2}$ photocatalysts under UV and visible light irradiations, Materials Research Bulletin, 47, 3697-3703.

Cardoso N.F., Lima E.C., Royer B., Bach M.V., Dotto G.L., Pinto L.A.A. and Calvete T. (2012), Comparison of Spirulina platensis microalgae and commercial activated carbon as adsorbents for the removal of Reactive Red 120 dye from aqueous effluents, Journal of Hazardous Materials, 241-242, 146-153.

Collazzo G.C., Foletto E.L., Jahn S.L. and Villetti M.A. (2012a), Degradation of Direct Black 38 dye under visible light and sunlight irradiation by $\mathrm{n}$-doped anatase $\mathrm{TiO}_{2}$ as photocatalyst, Journal of Environmental Management, 98, 107-111.

Collazzo G.C., Jahn S.L. and Foletto E.L. (2012b), Removal of Direct Black 38 dye by adsorption and photocatalytic degradation on $\mathrm{TiO}_{2}$ prepared at low temperature, Latin American Applied Research, 42, 55-60.

Dotto G.L. and Pinto L.A.A. (2012), Analysis of mass transfer kinetics in the biosorption of synthetic dyes onto Spirulina platensis nanoparticles, Biochemical Engineering Journal, 68, 85-90.

Dotto G.L., Costa J.A.V. and Pinto L.A.A. (2013), Kinetic studies on the biosorption of phenol by nanoparticles from Spirulina sp. LEB 18, Journal of Environmental Chemical Engineering, 1, 1137-1143.

Dotto G.L., Vieira M.L.G. and Pinto L.A.A. (2012), Kinetics and Mechanism of Tartrazine Adsorption onto Chitin and Chitosan, Industrial Engineering Chemistry Research, 51, 6862-6868.

El-Khaiary M.I. and Malash G.F. (2011), Common data analysis errors in batch adsorption studies, Hydrometallurgy, 105, 314-320.

El-Maghraby A. and El-Deeb H.A. (2011), Removal of a basic dye from aqueous solution by adsorption using rice hulls, Global NEST Journal, 13, 90-98.

Fil B.A., Karakas Z.K., Boncukcuoglu R. and Yilmaz A.E. (2013), Removal of cationic dye (Basic Red 18) from aqueous solution using natural Turkish clay, Global NEST Journal, 15, 529-541.

Ho Y.S. and McKay G. (1998), A comparison of chemisorption kinetic models applied to pollutant removal on various sorbents, Process Safety and Environmental Protection, 76, 332-340.

Kamboh M.A., Bhatti A.A., Solangi I.B., Sherazi S.T.H. and Memon S. (2014), Adsorption of Direct Black-38 azo dye on $p$ tert-butylcalix[6]arene immobilized material, Arabian Journal of Chemistry, 7, 125-131.

Lagergren S. (1898), About the theory of so-called adsorption of soluble substances, Kungliga Svenska Vetenskapsakad Handligar, 24, 1-39.

Leyva-Ramos R., Ocampo-Perez R. and Mendoza-Barron J. (2012), External mass transfer and hindered diffusion of organic compounds in the adsorption on activated carbon cloth, Chemical Engineering Journal, 183, 141-151.

Li Y.F., Zhang W.P., Li X.R. and Yu Y. (2014), $\mathrm{TiO}_{2}$ nanoparticles with high ability for selective adsorption and photodegradation of textile dyes under visible light by feasible preparation, Journal of Physics and Chemistry of Solids, 75, 86-93.

Liu Y. and Liu Y.J. (2008), Biosorption isotherms, kinetics and thermodynamics, Separation and Purification Technology, 61, 229-242. 
Moreira R.F.P.M., Sauer T.P., Casaril L. and Humeres E. (2005), Mass transfer and photocatalytic degradation of leather dye using $\mathrm{TiO}_{2} / \mathrm{UV}$, Journal of Applied Electrochemistry, 35, 821-829.

Paz D.S., Collazzo G.C., Mazutti M.A. and Foletto E. L. (2014), Influence of thermal treatment on the nitrogendoped $\mathrm{TiO}_{2}$ synthesis and its photocatalytic activity under visible light and solar irradiation, International Journal of Advanced Chemical Technology, 3, 19-22.

Ramesh S.T., Gandhimathi R., Elavarasi T.E., Thamizh R.I., Sowmya K. and Nidheesh P.V. (2014), Comparison of methylene blue adsorption from aqueous solution using spent tea dust and raw coir pith, Global NEST Journal, 16, 146-159.

Ruthven D.M. (1984), Principles of Adsorption and Adsorption Processes, John Wiley \& Sons, New York.

Saltabaş Ö., Taker M. and Konuk Z. (2012), Biosorption of cationic dyes from aqueous solution by water hyacinth roots, Global NEST Journal, 14, 24-31.

Sun J., Qiao L., Sun S. and Wang G. (2008), Photocatalytic degradation of orange G on nitrogen-doped $\mathrm{TiO}_{2}$ catalysts under visible light and sunlight irradiation, Journal of Hazardous Materials, 155, 312-319.

Sun H., Bai Y., Liu H., Jin W. and Xu N. (2009), Photocatalytic decomposition of 4-chlorophenol over an efficient Ndoped $\mathrm{TiO}_{2}$ under sunlight irradiation, Journal of Photochemistry and Photobiology A: Chemistry, 201, 15-22.

Uçar N.C.I. and Pazarlioglu N.K. (2008), Decolorization of Direct Black 38 by Abortiporus biennis, Journal of Biotechnology, 136s, s290-s344.

Verma V.K. and Mishra A.K. (2010), Kinetic and isotherm modeling of adsorption of dyes onto rice husk carbon, Global NEST Journal, 12, 190-196. 